Subscriber access provided by MPI FUR POLYMERFORSCHUNG

\title{
Communication
}

\section{Synthesis, Structure, and Chiroptical Properties of a Double [7]Heterohelicene}

\author{
Xiao-Ye Wang, Xin-Chang Wang, Akimitsu Narita, Manfred \\ Wagner, Xiao-Yu Cao, Xinliang Feng, and Klaus Müllen
}

J. Am. Chem. Soc., Just Accepted Manuscript • DOI: 10.1021/jacs.6b08664 • Publication Date (Web): 22 Sep 2016

Downloaded from http://pubs.acs.org on September 26, 2016

\section{Just Accepted}

"Just Accepted" manuscripts have been peer-reviewed and accepted for publication. They are posted online prior to technical editing, formatting for publication and author proofing. The American Chemical Society provides "Just Accepted" as a free service to the research community to expedite the dissemination of scientific material as soon as possible after acceptance. "Just Accepted" manuscripts appear in full in PDF format accompanied by an HTML abstract. "Just Accepted" manuscripts have been fully peer reviewed, but should not be considered the official version of record. They are accessible to all readers and citable by the Digital Object Identifier (DOI®). "Just Accepted" is an optional service offered to authors. Therefore, the "Just Accepted" Web site may not include all articles that will be published in the journal. After a manuscript is technically edited and formatted, it will be removed from the "Just Accepted" Web site and published as an ASAP article. Note that technical editing may introduce minor changes to the manuscript text and/or graphics which could affect content, and all legal disclaimers and ethical guidelines that apply to the journal pertain. ACS cannot be held responsible for errors or consequences arising from the use of information contained in these "Just Accepted" manuscripts. 
Helicenes, which are screw-shaped helical $\pi$-skeletons with orthofused aromatic rings, have attracted continuous attention due to their inherent chirality that has led to promising applications in asymmetric catalysis, molecular recognition, molecular machines, and chiroptical devices. ${ }^{1}$ With more ortho-annulated rings, the helical $\pi$-system starts to form additional layers, i.e., the helicene skeleton covers more than one whole rotation of a helical twist $\left(360^{\circ}\right) .[n]$ Carbohelicenes, where $n$ represents the number of ortho-fused benzene rings, exhibit a double layer when $n=7$ and a triple layer when $n=13 .{ }^{2}$, During the past decades, significant progress has been made in pushing the limit of higher homologues of $[n]$ helicenes, ${ }^{3}$ and $[16]$ carbohelicene was achieved in 2015 as a new record. ${ }^{4}$ While carbohelicenes have dominated the helicene chemistry over the past century, heterohelicenes have recently emerged as a new class of attractive molecules through incorporation of heteroatoms in the helical frameworks, providing different catalytic and optoelectronic properties as well as new synthetic entries to such chiroptically active skeletons. ${ }^{5}$

On the other hand, helicenes with multihelicity can offer diverse conformations, increased nonplanarity, and three-dimensional intermolecular interactions. ${ }^{6}$ In particular, intensive effort has been devoted to the synthesis of double helicenes (structures with two helicenes fused together), including both double carbohelicenes ${ }^{7}$ and double heterohelicenes $^{8}$ (Figure 1). However, double helicenes thus far re-

ported are only single layered structures. As to double helicenes with all six-membered rings, their length is limited to double [6] helicene while thiophene-fused double [7] helicene was reported as the longest double helicenes by incorporating five-membered rings, ${ }^{9}$ which nevertheless do not establish overlap between the terminal aromatic rings due to the smaller turning angle of five-membered rings. Compared to the inspiring advances in the synthesis of double- and even triple-layered monohelicenes, a double helicene with layered structures at both ends has remained elusive due to the challenge in synthesis

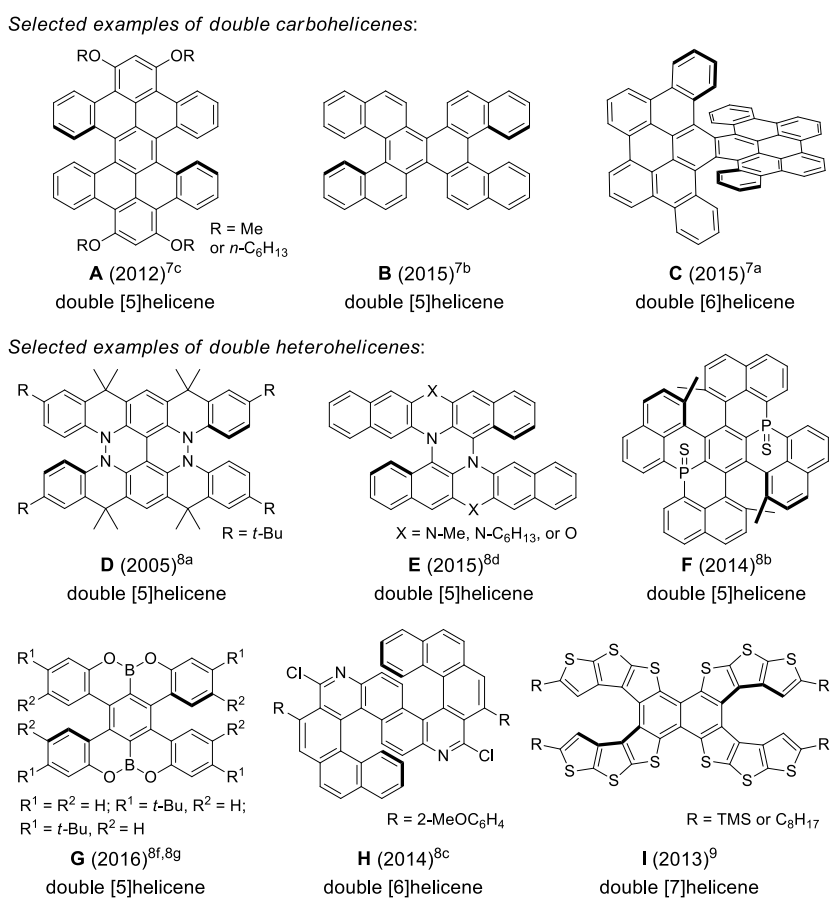

Figure 1. Representative examples of double helicenes.

Herein, we report the first example of a layered double helicene, a highly strained OBO-fused double [7] helicene 1 with all six-membered rings (Scheme 1). Single crystal X-ray analysis elucidated a substantial overlap between the terminal benzene rings, which provided the highest reported isomerization barrier for double helicenes as revealed by 
DFT calculations and thus excellent chiral stability, facilitating the successful optical resolution of the chiral isomers.

Scheme 1. Synthetic route to double [7]heterohelicene 1.

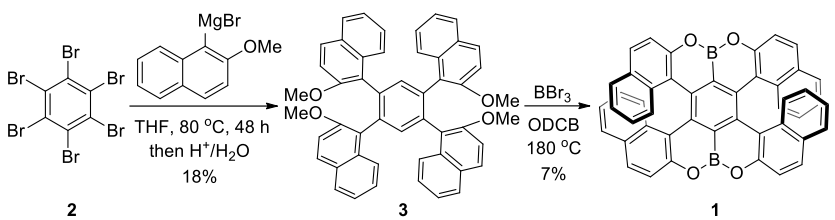

Recently, Hatakeyama et al. and our group independently reported the skeleton of 9a,19a-dibora-9,10,19,20tetraoxatetrabenzo $[a, f, j, o]$ perylene, that is, a double [5]heterohelicene G (Figure 1) through different methods. ${ }^{8 f, 8 g}$ In this work, we demonstrate the synthesis of the unprecedented double [7]helicene 1 via tandem reactions of demethylation and direct $\mathrm{C}-\mathrm{H}$ aryl borylation (Scheme 1). ${ }^{8 g, 10}$ Hexabromobenzene 2 was treated with (2methoxynaphthalen-1-yl)magnesium bromide in THF for $48 \mathrm{~h}$ followed by quenching with dilute hydrochloric acid to provide $1,2,4,5$ tetrakis(2-methoxynaphthalen-1-yl)benzene (3) in 18\% yield. Then a solution of compound 3 in $o$-dichlorobenzene (ODCB) was heated in the presence of $\mathrm{BBr}_{3}$ at $180{ }^{\circ} \mathrm{C}$ to build up the OBO-fused double [7] helicene $\mathbf{1}$ in $7 \%$ yield after purification by column chromatography. The yield is apparently much lower than that in the case of double [5] helicene $\mathbf{G}$ (over $90 \%$ ), ${ }^{8 g}$ probably because of the high strain during the ring closure. The chemical structure of double [7] helicene 1 was characterized by ${ }^{1} \mathrm{H},{ }^{13} \mathrm{C}$, and $2 \mathrm{D}$ NMR as well as high-resolution MALDI-TOF MS. A well-resolved ${ }^{1} \mathrm{H}$ NMR spectrum was obtained in THF- $d_{8}$ (see the Supporting Information). It is noteworthy that the signals assigned to the naphthalene $\beta$-positions on the terminal rings appeared at 6.88 and $6.57 \mathrm{ppm}$, reflecting the $\pi$-overlap at the terminal rings, which resulted in a high shielding effect. (a)

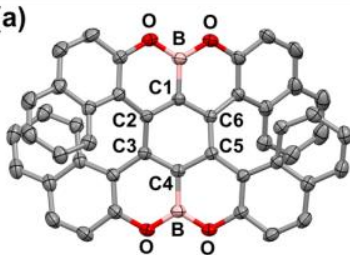

(b)

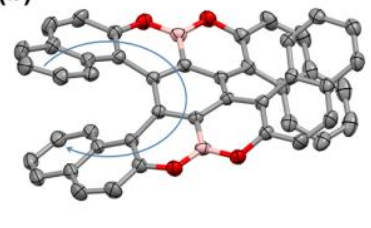

(c)

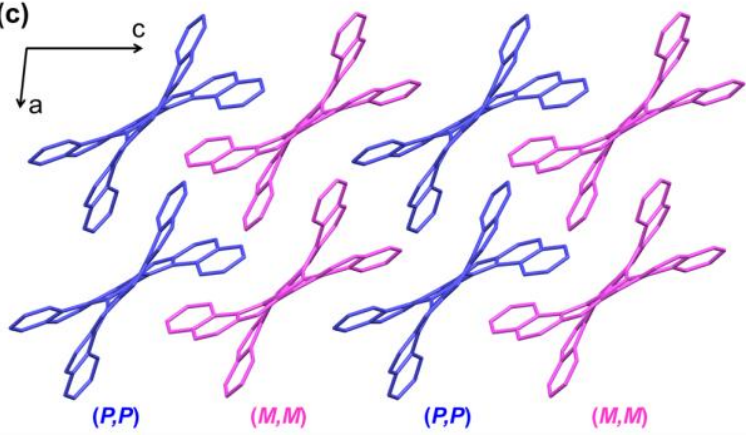

Figure 2. Single crystal structure of OBO-fused double [7] helicene 1. (a) Top view and (b) side view of $(P, P)-1$. Thermal ellipsoids are shown at $50 \%$ probability. Hydrogen atoms are omitted for clarity. (c) Crystal packing structure of $\mathbf{1}$ viewed along the $b$ axis.

The single crystal of compound 1 was grown by slow evaporation of its solution in $\mathrm{CH}_{2} \mathrm{Cl}_{2}$ /hexane and its double [7] helicene structure unambiguously determined by X-ray crystallography. As depicted in Figure 2, two [7] heterohelicene substructures are fused together, sharing a common benzene ring. Seven ortho-annulated six-membered rings clearly cover more than one circle of a helical turn, with the two terminal benzene rings overlapping onto each other. The pitch distance, which is defined as the average distance between the outer rim atoms from different layers, is $4.63 \AA$, close to the value of [7]carbohelicene $(4.64 \AA) .{ }^{11}$ The layered structure makes the molecule more twisted than the OBO-fused double [5] helicene G. In addition, the central benzene ring is highly distorted, with the dihedral angles of $27.8^{\circ}$ for C1-C2-C3-C4, $28.7^{\circ}$ for C1-C6-C5-C4, and $26.5^{\circ}$ for C2-C3-C5-C6 $\left(23.5^{\circ}, 24.6^{\circ}\right.$, and $22.3^{\circ}$, respectively, for those of compound $\left.\mathrm{G}\right){ }^{8 \mathrm{~g}}$ The bond lengths of the central benzene ring (e.g. C1-C2: 1.411 $\AA$; C2-C3: $1.427 \AA$; C3-C4: $1.409 \AA$ ) are also longer than those of planar benzene (about $1.39 \AA$ ), indicating the $\pi$-distortion. Nucleus-independent chemical shift (NICS) calculations revealed the low aromaticity of the central benzene with a NICS (0) value of $-4.9 \mathrm{ppm}$ (Figure S3), much lower than that of benzene $(-7.6 \mathrm{ppm}$, calculated at the same level of theory) as a result of the strong distortion. In one unit cell, two enantiomers, $(P, P)-1$ and $(M, M)-1$ are present in a ratio of $1: 1$. As illustrated in Figure $2 c$, homochiral molecules are packed along the $a$ axis, whereas along the $c$ axis, heterochiral molecules are packed alternately.

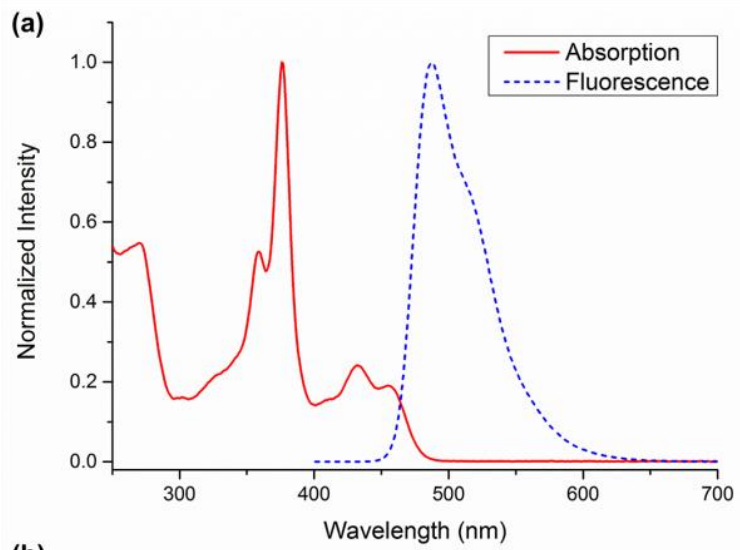

(b)

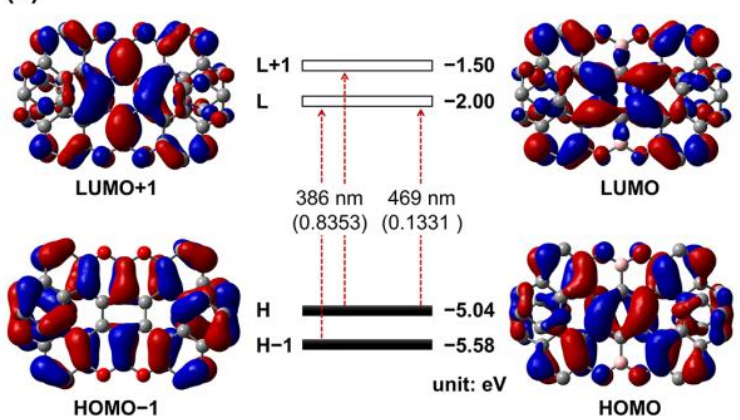

Figure 3. (a) Normalized absorption and emission spectra of compound 1 in $\mathrm{CH}_{2} \mathrm{Cl}_{2}$ solutions. (b) Molecular orbitals and their energy diagrams calculated by TD-DFT at the B3LYP/6-31G(d) level. H: HOMO; L: LUMO.

The absorption spectrum of 1 recorded in $\mathrm{CH}_{2} \mathrm{Cl}_{2}$ solutions (Figure 3) exhibited a maximum at $376 \mathrm{~nm}$ (absorption coefficient: $6.2 \times 10^{4}$ $\mathrm{M}^{-1} \mathrm{~cm}^{-1}$ ) which is significantly red shifted compared with that of double [5] helicene $\mathbf{G}(310 \mathrm{~nm}){ }^{8 \mathrm{~g}}$ The absorption onset of $\mathbf{1}$ is $479 \mathrm{~nm}$, corresponding to an optical energy gap of $2.59 \mathrm{eV}$, which is lower than that of double [5]helicene $\mathrm{G}(2.88 \mathrm{eV})$ due to the extended $\pi$ conjugation. According to TD-DFT calculations, the low-energy absorption band from 400 to $500 \mathrm{~nm}$ is assignable to the HOMO $\rightarrow$ LUMO transition. The band at $376 \mathrm{~nm}$ is attributed to almost equal contributions of HOMO- $\rightarrow$ LUMO and $\mathrm{HOMO} \rightarrow \mathrm{LUMO}+1$ transitions. These orbitals are delocalized over 
the entire double helicene skeleton, and boron atoms play an important role in HOMO-1 and LUMO+1. Compound 1 displayed a green-yellow fluorescence with the emission maximum at $487 \mathrm{~nm}$ and a quantum yield of $26 \%$.

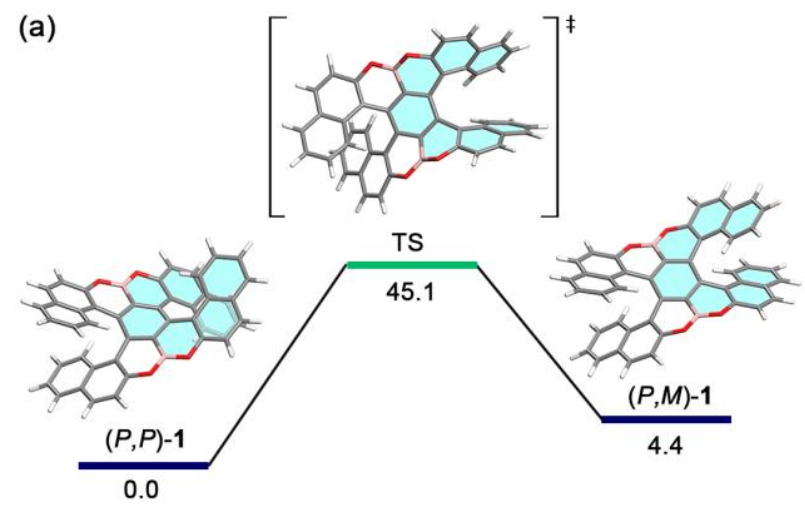

(b)

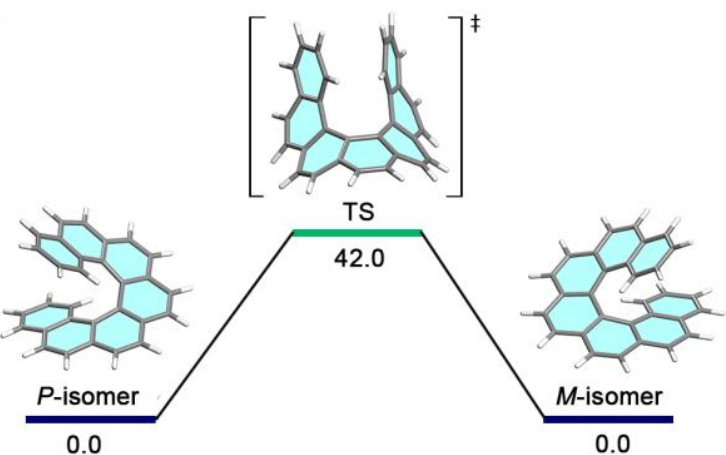

Figure 4. Isomerization process of (a) double helicene 1 from $(P, P)$ isomer to $(P, M)$-isomer and (b) $[7]$ carbohelicene from $P$-isomer to $M$ isomer. The relative Gibbs free energy $(\mathrm{kcal} / \mathrm{mol})$ was calculated at the B3LYP/6-31G(d) level.

The isomerization process of double [7] helicene 1 was further studied by DFT calculations at the B3LYP/6-31G(d) level. As illustrated in Figure 4, the twisted $(P, P)$ - or $(M, M)$ - conformation is thermodynamically more stable than the $(P, M)$-conformation by $4.4 \mathrm{kcal} / \mathrm{mol}$, which is consistent with the fact that only $(P, P)$ - and $(M, M)$-isomers were experimentally observed. The isomerization from the chiral $(P, P)$ - or $(M, M)$-isomer to the achiral $(P, M)$-isomer proceeds through the transition state (TS) where the terminal benzene rings are oriented in a face-to-face manner. The energy barrier for the isomerization process is calculated to be $45.1 \mathrm{kcal} / \mathrm{mol}$, which is the highest among the values for all reported double helicenes. ${ }^{7 a, 7 b}$ Notably, the isomerization barrier of the OBO-fused double [7] helicene is higher than that of [7] carbohelicene $(42.0 \mathrm{kcal} / \mathrm{mol})$, indicating the advantage of double helicenes over monohelicenes in terms of conformational stability.

The high isomerization barrier enabled the optical resolution of double [7] helicene 1 by using chiral HPLC on a Daicel Chiralcel IE column (eluent: EtOAc/MeOH = 9:1). Two peaks were observed in the chiral HPLC analysis (see the Supporting Information), corresponding to the two enantiomers of $\mathbf{1}$. After the separation by preparative chiral HPLC, the circular dichroism (CD) spectra of the two isolated fractions displayed perfect mirror symmetry, indicating that they are enantiomers with opposite helicity (Figure 5). The simulated CD spectra of $(P, P)-1$ and $(M, M)$-1 were in good agreement with the experimental results, and revealed that the first peak corresponded to $(M, M)$-isomer and the second peak to $(P, P)$-isomer. In order to exam- ine the chiral stability of double [7] helicene 1, enantiomer $(P, P)-1$ and $(M, M)-1$ were respectively heated up to $200^{\circ} \mathrm{C}$ and monitored by chiral HPLC. No racemization was observed for $24 \mathrm{~h}$, highlighting good conformational stability due to the high isomerization barrier.
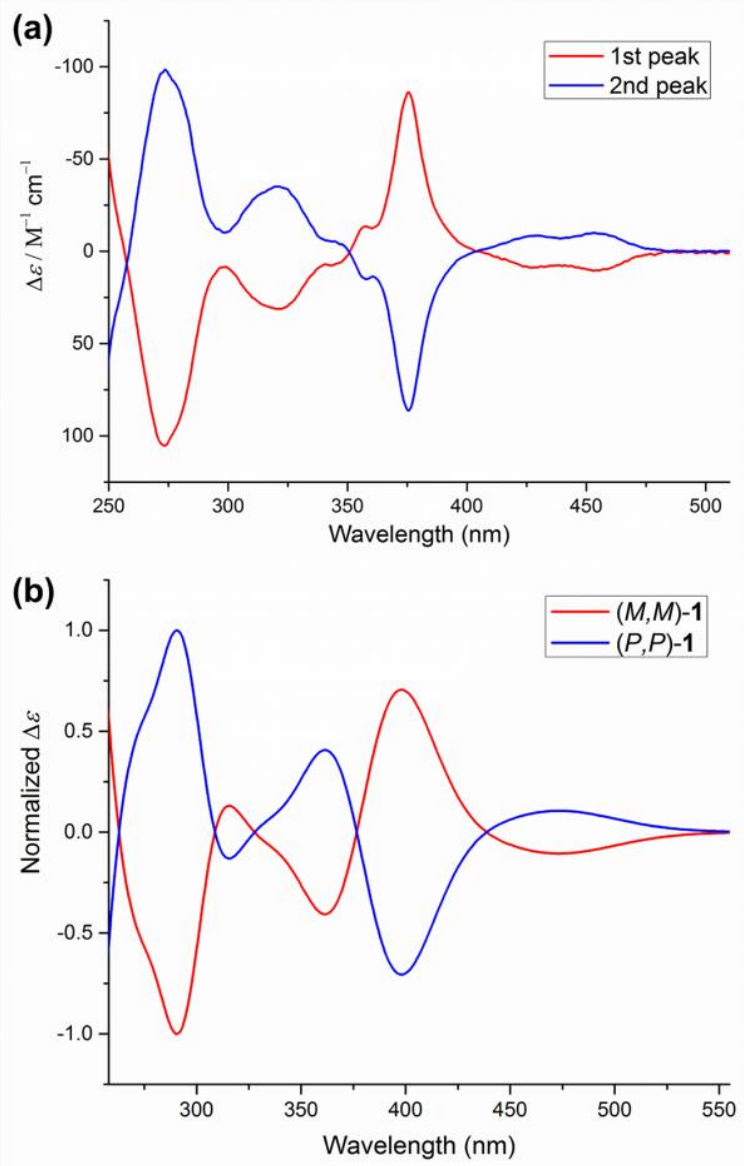

Figure 5. (a) CD spectra of the two enantiomers of 1 separated by chiral HPLC in $\mathrm{CH}_{2} \mathrm{Cl}_{2}$. (b) Simulated CD spectra of $(P, P)-1$ and $(M, M)-1$ based on TD-DFT calculations at the B3LYP/6-31G(d) level.

In summary, the first double [7]helicene with all ortho-fused sixmembered rings has been achieved, inspite of the high strain built up in the synthesis. As evidenced by NMR analysis and X-ray crystallography, the terminal aromatic rings of the OBO-fused double [7] helicene exhibited significant overlaps at both ends, representing the first example of a layered double helicene. This feature endowed the molecule with the highest isomerization energy barrier $(45.1 \mathrm{kcal} / \mathrm{mol})$ among all reported double helicenes. The enantiomers were separated by chiral HPLC, exhibiting mirror-image CD spectra, which are consistent with DFT modelling. This work has demonstrated the efficacy of the direct aryl $\mathrm{C}-\mathrm{H}$ borylation method in the synthesis of highly strained molecules, and will stimulate more efforts on pushing the limit towards higher double helicenes and further exploring their functional properties.

\section{ASSOCIATED CONTENT}

\section{Supporting Information}

The Supporting Information is available free of charge on the ACS Publications website.

Experimental details and data (PDF) 
Crystallographic data for 1 (CIF)

\section{AUTHOR INFORMATION}

\section{Corresponding Author}

narita@mpip-mainz.mpg.de

xcao@xmu.edu.cn

muellen@mpip-mainz.mpg.de

\section{Notes}

The authors declare no competing financial interests.

\section{ACKNOWLEDGMENT}

The authors sincerely thank Dr. Dieter Schollmeyer (Institute for Organic Chemistry, Johannes Gutenberg University Mainz) for singlecrystal X-ray structural analysis. Xiao-Ye Wang is grateful for the fellowship from Alexander von Humboldt Foundation. We acknowledge the financial support from European Commission through the FETProactive Project "MoQuaS", contract N.610449 and Graphene Flagship (No. CNECT-ICT-604391).

\section{REFERENCES}

(1) (a) Shen, Y.; Chen, C.-F. Chem. Rev. 2012, 112, 1463. (b) Gingras, M. Chem. Soc. Rev. 2013, 42, 968. (c) Gingras, M.; Felix, G.; Peresutti, R. Chem. Soc. Rev. 2013, 42, 1007. (d) Gingras, M. Chem. Soc. Rev. 2013, 42, 1051.

(2) (a) Schulman, J. M.; Disch, R. L.J. Phys. Chem. A 1999, 103, 6669. (b) Tian, Y.-H.; Park, G.; Kertesz, M. Chem. Mater. 2008, 20, 3266.

(3) (a) Hoffmann, N. J. Photochem. Photobiol. C 2014, 19, 1. (b) Martin, R. H.; Morren, G.; Schurter, J. J. Tetrahedron Lett. 1969, 10, 3683. (c) Martin, R. H.; Baes, M. Tetrahedron 1975, 31, 2135.

(4) Mori, K.; Murase, T.; Fujita, M. Angew. Chem. Int.Ed. 2015, 54, 6847.

(5) (a) Rajca, A.; Wang, H.; Pink, M.; Rajca, S. Angew. Chem. Int. Ed. 2000, 39, 4481. (b) Miyasaka, M.; Rajca, A.; Pink, M.; Rajca, S. J. Am. Chem. Soc. 2005, 127, 13806. (c) Nakano, K.; Hidehira, Y.; Takahashi, K.; Hiyama, T.; Nozaki, K. Angew. Chem. Int. Ed. 2005, 44, 7136. (d) Tanaka, K.; Fukawa, N.; Suda, T.; Noguchi, K. Angew. Chem. Int. Ed. 2009, 48, 5470. (e) Pieters, G.; Gaucher, A.; Marque, S.; Maurel, F.; Lesot, P.; Prim, D. J. Org. Chem. 2010, 75, 2096. (f) Hatakeyama, T.; Hashimoto, S.; Oba, T.; Nakamura, M. J.Am. Chem. Soc. 2012, 134, 19600. (g) Kelgtermans, H.; Dobrzańska, L.; Meervelt, L. V.; Dehaen, W. Org. Lett. 2012, 14, 1500. (h) Nakano, K.; Oyama, H.; Nishimura, Y.; Nakasako, S.; Nozaki, K. Angew. Chem. Int. Ed. 2012, 51, 695. (i) Žádný, J.; Jančařík, A.; Andronova, A.; Šámal, M.; Vacek Chocholoušová, J.; Vacek, J.; Pohl, R.; Šaman, D.; Císařová, I.; Stará, I. G.; Starý, I. Angew. Chem. Int. Ed. 2012, 51, 5857. (j) Gicquel, M.; Zhang, Y.; Aillard, P.; Retailleau, P.; Voituriez, A.; Marinetti, A. Angew. Chem. Int. Ed. 2015, 54, 5470. (k) Shyam Sundar, M.; Bedekar, A. V. Org. Lett. 2015, 17, 5808. (1) Schickedanz, K.; Trageser, T.; Bolte, M.; Lerner, H.-W.; Wagner, M. Chem. Commun. 2015, 51, 15808. (m) Miyamoto, F.; Nakatsuka, S.; Yamada, K.; Nakayama, K.-i.; Hatakeyama, T. Org. Lett. 2015, 17,6158 .

(6) (a) Fujikawa, T.; Segawa, Y.; Itami, K. J. Am. Chem. Soc. 2016, 138, 3587. (b) Zhong, Y.; Trinh, M. T.; Chen, R.; Purdum, G. E.; Khlyabich, P. P.; Sezen, M.; Oh, S.; Zhu, H.; Fowler, B.; Zhang, B.; Wang, W.; Nam, C.-Y.; Sfeir, M. Y.; Black, C. T.; Steigerwald, M. L.; Loo, Y.-L.; Ng, F.; Zhu, X. Y.; Nuckolls, C. Nat. Commun. 2015, 6, 8242. (c) Ball, M.; Zhong, Y.; Wu, Y.; Schenck, C.; Ng, F.; Steigerwald, M.; Xiao, S.; Nuckolls, C. Acc. Chem. Res. 2015, 48, 267. (d) Xiao, S.; Kang, S. J.; Wu, Y.; Ahn, S.; Kim, J. B.; Loo, Y.-L.; Siegrist, T.; Steigerwald, M. L.; Li, H.; Nuckolls, C. Chem. Sci. 2013, 4, 2018. (e) Meng, L.; Fujikawa, T.; Kuwayama, M.; Segawa, Y.; Itami, K. J. Am. Chem. Soc. 2016, 138, 10351. (f) Meng, D.; Fu, H.; Xiao, C.; Meng, X.; Winands, T.; Ma, W.; Wei, W.; Fan, B.; Huo, L.; Doltsinis, N. L.; Li, Y.; Sun, Y.; Wang, Z. J. Am. Chem. Soc. 2016, 138, 10184.

(7) (a) Fujikawa, T.; Segawa, Y.; Itami, K. J. Am. Chem. Soc. 2015, 137, 7763. (b) Kashihara, H.; Asada, T.; Kamikawa, K. Chem. Eur. J. 2015, 21, 6523. (c) Luo, J.; Xu, X.; Mao, R.; Miao, Q.J.Am. Chem. Soc. 2012, 134, 13796. (d) Lütke Eversloh, C.; Liu, Z.; Müller, B.; Stangl, M.; Li, C.; Müllen, K. Org. Lett. 2011,
13, 5528. (e) Peña, D.; Cobas, A.; Pérez, D.; Guitián, E.; Castedo, L. Org. Lett. 2003, 5, 1863.

(8) (a) Shiraishi, K.; Rajca, A.; Pink, M.; Rajca, S. J. Am. Chem. Soc. 2005, 127, 9312. (b) Hashimoto, S.; Nakatsuka, S.; Nakamura, M.; Hatakeyama, T. Angew. Chem. Int. Ed. 2014, 53, 14074. (c) Nakamura, K.; Furumi, S.; Takeuchi, M.; Shibuya, T.; Tanaka, K. J. Am. Chem. Soc. 2014, 136, 5555. (d) Sakamaki, D.; Kumano, D.; Yashima, E.; Seki, S. Angew. Chem. Int. Ed. 2015, 54, 5404. (e) Sakamaki, D.; Kumano, D.; Yashima, E.; Seki, S. Chem. Commun. 2015, 51, 17237. (f) Katayama, T.; Nakatsuka, S.; Hirai, H.; Yasuda, N.; Kumar, J.; Kawai, T.; Hatakeyama, T. J. Am. Chem. Soc. 2016, 138, 5210. (g) Wang, X.-Y.; Narita, A.; Zhang, W.; Feng, X.; Müllen, K.J. Am. Chem. Soc. 2016, 138, 9021.

(9) (a) Liu, X.; Yu, P.; Xu, L.; Yang, J.; Shi, J.; Wang, Z.; Cheng, Y.; Wang, H. J. Org. Chem. 2013, 78, 6316. (b) Wang, Z.; Shi, J.; Wang, J.; Li, C.; Tian, X.; Cheng, Y.; Wang, H. Org. Lett. 2010, 12, 456.

(10) Numano, M.; Nagami, N.; Nakatsuka, S.; Katayama, T.; Nakajima, K.; Tatsumi, S.; Yasuda, N.; Hatakeyama, T. Chem. Eur. J. 2016, 22, 11574.

(11) Rulišek, L.; Exner, O.; Cwiklik, L.; Jungwirth, P.; Starý, I.; Pospišsil, L.; Havlas, Z.J. Phys. Chem. C 2007, 111, 14948. 
1

2

3

4

5

6

8

9

10

11

12

13

14

15

16

17

18

19

20

21

22

23

24

25

26

27

28

29

30

31

32

33

34

35

36

37

38

39

40

41

42

43

44

45

46

47

48

49

50

51

52

53

54

55

56

57

58

59

60

Table of Contents Graphic

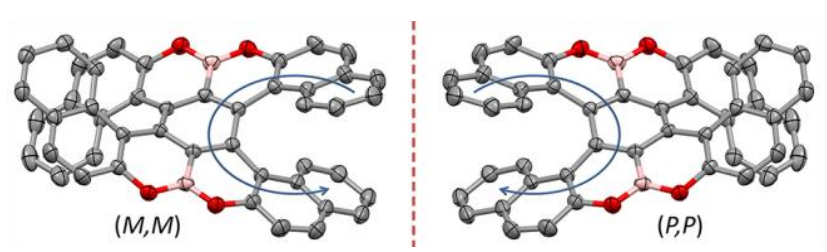

